\title{
AUTOCUIDADO E O ADULTO PORTADOR DE ASMA: SISTEMATIZAÇÃO DA ASSISTÊNCIA DE ENFERMAGEM ${ }^{1}$
}

\author{
SELF-CARE AND THE ADULT WITH ASTHMA: THE SISTEMATIZATION OF NURSING \\ ASSISTANCE
}

\author{
AUTOCUIDADO Y EL ADULTO PORTADOR DE ASMA: SISTEMATIZACIÓN DE LA ASISTENCIA \\ DE ENFERMERÍA
}

\author{
Estela Maria Leite Meirelles Monteiro² \\ Maria Miriam Lima da Nóbrega ${ }^{3}$ \\ Luciane Soares de Lima ${ }^{4}$
}

RESUMO: Por meio desta pesquisa, objetivamos sistematizar a assistência de enfermagem à luz da Teoria de Enfermagem do Déficit de Autocuidado de Orem. Para desenvolvê-la, utilizamos a pesquisa convergente-assistencial, através da operacionalização do processo de enfermagem em um adulto portador de asma. Utilizamos as técnicas de entrevista, exame físico, observação e o registro de informações, tendo realizado acompanhamento ambulatorial de enfermagem e visitas domiciliares. Durante o desenvolvimento do processo de enfermagem, levantamos os déficit de autocuidado e traçamos o plano assistencial, com o estabelecimento das metas, dos objetivos, tendo escolhido o sistema e os métodos de ajuda. Executamos o plano assistencial com a implementação da assistência de enfermagem, priorizando ações de apoio educação. Com base nos resultados, concluímos ser pertinente e viável a aplicabilidade do processo de enfermagem à luz do referencial de autocuidado de Orem, visando o engajamento da cliente e de seus familiares no autocuidado.

PALAVRAS-CHAVE: autocuidado, asma, enfermagem

ABSTRACT: This research aims at the systematization of nursing assistance under Orem's nursing theory of self-care deficit. In order to conduct this study, the convergent approach was used through the performance of the nursing processes in an adult with asthma. Interviews, physical examinations, observations, data record, observation of nursing assistance in policlinics along with home visits were the techniques used to gather data. After the observation of the nursing assistance, self-care deficits were identified and a new assistance plan and objectives were established, as well as a system and methods of support. The assistance plan was performed through the implementation of nursing assistance, prioritizing educational support. Based on the results, it was concluded that the application of the nursing processes through Orem's self-care referential is feasible and necessary for the engagement of clients and their family in self-care.

KEYWORDS: self-care, asthma, nursing

RESUMEN: Esta investigación tiene como objetivo sistematizar la asistencia de enfermeria a la luz de la Teoría de Enfermería del Déficit de Autocuidado de Orem. Para desarrollarla se utilizó la investigación convergente-asistencial, a través de la operacionalización del proceso de enfermeria a un adulto portador de asma. Se utilizaron las técnicas de entrevista, examen físico, observación y el registro de informaciones, con un acompañamiento ambulatorial de enfermería y visitas domiciliares. Durante el desarrollo del proceso de enfermería se levantaron los déficits de autocuidado, dibujamos el plan de asistencia con el establecimiento de las metas, los objetivos y el sistema y los métodos de ayuda. Ejecutamos el plan asistencial con la implementación de la asistencia de enfermería, dando prioridad a las acciones de apoyo educación. Con base en los resultados, concluimos que es pertinente y viable la aplicabilidad del proceso de enfermeria bajo la perspectiva del referencial de autocuidado de Orem, con vistas a que la cliente y sus familiares participen en su autocuidado.

PALABRAS CLAVE: autocuidado, asma, enfermería

Recebido em 22/02/2002

Aprovado em 26/06/2002

\footnotetext{
1 Trabalho extraído de Dissertação de Mestrado desenvolvida e aprovada no Programa de Pós-Graduação em Enfermagem do Centro de Ciências da Saúde da Universidade Federal da Paraíba.

${ }^{2}$ Enfermeira. Mestre em Enfermagem pela UFPB. Professora da Faculdade de Enfermagem Nossa Senhora das Graças da Universidade de Pernambuco - UPE.

${ }^{3}$ Enfermeira. Doutora em Enfermagem pela UNIFESP. Professora do Departamento de Enfermagem de Saúde Pública e Psiquiatria da Universidade Federal da Paraiba - UFPB. Orientadora da Dissertação.

${ }^{4}$ Enfermeira. Doutora em Enfermagem pela UNIFESP. Professora do Departamento de Enfermagem da Universidade Federal de Pernambuco - UFPE. Orientadora da Dissertação.
} 


\section{INTRODUÇÃO}

Dentre as doenças crônicas que prevalecem na comunidade, em geral, há evidências de que a asma esteja tornando-se cada vez mais grave, desencadeando atendimentos em unidades de emergência e limitação da produtividade de seus portadores, provocando prejuízo econômico a eles, à comunidade e ao governo (RICHARDS, 1989). Para Nettina (1997), a asma é uma doença obstrutiva das vias aéreas, condição recorrente dos pulmões, quase completamente reversível, caracterizada por maior responsividade ou irritabilidade da traquéia e dos brônquios, como resposta a vários estímulos, cuja gravidade é modificada, tanto espontaneamente, quanto com tratamento.

Os estudos epidemiológicos, no Brasil, referentes à asma são poucos, desconhecendo-se, desse modo, a verdadeira dimensão da doença, nas diferentes regiões do país, fato que dificulta muito o planejamento e execução de programas que visem a sua prevenção (NORONHA et al., 1996; PEREIRA etal., 1998). No ano 2000, ocorreram cerca de 397.000 internações, por asma, no pais, onde a Região Nordeste liderou, com aproximadamente 165.000 internações, seguida pela Região Sudeste, com quase cem mil. Vale ressaltar que a Região Sudeste vem apresentando um discreto decréscimo na taxa de internação, nos últimos três anos, de 1,41\%, enquanto, na Região Nordeste, esse indice vem-se elevando em cerca de 19,56\% (BRASIL, 2001).

$A$ atuação de enfermagem ao cliente portador de asma brônquica deve privilegiar a prevenção e a intervenção precoce, através do desenvolvimento de ações educativas, propiciando maior conhecimento da doença, identificação de seus fatores desencadeantes, precauções necessárias ao seu controle, tratamento, habilidade no uso dos dispositivos para inalação, plano de ação na crise, identificação da situação de seu descontrole, importância da adesão do povo ao tratamento visando à melhora do estado clínico e à minimização das crises.

Compreendendo a complexidade de alterações biopsicossocias manifestadas pelos portadores de asma brônquica e a necessidade do desenvolvimento de um trabalho educativo de modo a estimular e propiciar, ao cliente, seu autocuidado, descobre-se um campo de ação bastante favorável à atuação da enfermeira, ressaltando seu papel de educador/agente de mudança. Diante dos fundamentos expostos, o estudo tem o objetivo de sistematizar a assistência de enfermagem desenvolvida ao adulto portador de asma brônquica à luz da Teoria de Enfermagem do Déficit de Autocuidado de Orem.

\section{METODOLOGIA}

Visando o desenvolvimento de um trabalho que contribua para o aperfeiçoamento do fazer técnico e do agir ético, optamos por uma pesquisa convergente-assistencial, que aproxima a prática profissional do conhecimento teórico, valorizando a subjetividade e o sentimento como elementos essenciais, de modo que o pesquisador constitui sujeito partícipe do fazer científico (TRENTINI ; PAIM, 1999).

A execução desta pesquisa atendeu à etapa prévia, de apreciação, por parte dos Comitês de Ética em Pesquisa da Universidade Federal da Paraíba e do Hospital Universitário
Oswaldo Cruz, da Universidade de Pernambuco, conforme com a Resolução 196/96 (BRASIL, 1996).

Desenvolvemos o estudo com uma cliente portadora de asma no Ambulatório de um Hospital Universitário da cidade de Recife-PE, que aceitou participar do estudo, com sua autorização formal, tendo assinado o Termo de Consentimento Livre e Esclarecido. Vale ressaltar que o cenário deste estudo não se limitou ao ambiente formal da instituição de saúde, devido à realização de visitas domiciliares, que contribuíram, não só para o estabelecimento de uma maior interação enfermeira-cliente e seus familiares, como também, para possibilitar uma pertinência na constatação e apreensão das situações peculiares à realidade do ambiente residencial do cliente.

Com o intuito de estabelecer técnicas de pesquisa mais adequadas à realidade prática assistencial, utilizamos a técnica de entrevista, o exame físico, a observação e o registro de informações. Para levantamento dos dados utilizamos, como instrumento, um roteiro de entrevista estruturado, que foi testado e submetido à apreciação de especialistas, resultando em várias reformulações no instrumento, visando, não só atender o enfoque teórico que subsidiou e respaldou a aplicação do processo de enfermagem como, também, contemplar, com consistência, questões inerentes ao objeto investigado.

O desenvolvimento da etapa de levantamento de dados compreendeu a apreensão de informações referentes ao cliente, pertinentes aos requisitos de autocuidado universal, requisitos de autocuidado relativos ao desenvolvimento e requisitos de autocuidado referentes às alterações de saúde. Essa etapa corresponde à fase de perscrutação do estudo, constituindo alicerce para o estabelecimento das demais fases do processo, que se encontram inter-relacionadas e superpostas de forma cíclica.

Para Orem (1995), os diagnósticos resultam da relação existente ou projetada entre o acúmulo de fatos sobre a ação de autocuidado do cliente e sua demanda terapêutica de autocuidado, através do qual, neste trabalho, identificamos os déficit de autocuidado em uma cliente portadora de asma. Considerando a evolução que vêm alcançando os sistemas de classificação dos diagnósticos de enfermagem, na atualidade, utilizamos o Sistema de Classificação de Fenômenos de Enfermagem da CIPE, Versões Alfa (NÓBREGA; GUTIÉRREZ, 2000) e Beta (ICN, 1999) e a Taxonomia da NANDA (2000), para construção/denominação dos diagnósticos de enfermagem.

A partir da identificação desses diagnósticos, iniciamos a fase de planejamento da assistência de enfermagem, com o objetivo de estabelecer as metas e os objetivos, selecionar o sistema de enfermagem e os métodos de ajuda a serem utilizados, viabilizando a execução das intervenções de enfermagem propostas, com base nos conhecimentos teóricos específicos que subsidiam a prática, como também, em nossa experiência profissional.

A execução do plano assistencial faz-se a partir da implementação da assistência de enfermagem, de modo que, a assistência desenvolvida enfocou ações de apóio-educação junto à cliente do estudo, visando manter a provisão contínua de cuidados de saúde.

$\mathrm{Na}$ etapa de avaliação ocorre uma ação contínua coparticipativa, onde enfermeira e clientes desenvolvem uma 
análise da situação de saúde apresentada. Assim, juntamente com a cliente portadora de asma, buscamos identificar se a mesma havia alcançado as metas e os objetivos preestabelecidos, na promoção de seu autocuidado, possibilitando-a reconhecer a necessidade de ajustes e mudanças na assistência planejada.

\section{OPERACIONALIZANDO O PROCESSO DE ENFERMAGEM}

Os dados coletados com a aplicação do processo de enfermagem, à luz da Teoria de Enfermagem do Déficit de Autocuidado, foram organizados e descritos, com ênfase na identificação dos déficit de autocuidado e escolha do sistema de enfermagem e na avaliação da assistência de enfermagem na promoção do autocuidado. Para respeitar as questões éticas e garantir o anonimato da participante na pesquisa, utilizaremos a alcunha de Nina, por ela sugerida, para sua identificação no estudo.

\section{Caso Nina}

Tem 41 anos, cursou até o segundo ano do ensino médio, possui três filhos (de 20, 17 e 15 anos) e vive com seu companheiro, há 20 anos, de quem fala com muito carinho o qual, atualmente, encontra-se desempregado. Sempre muito ativa, já trabalhou em orfanato e asilio, auxiliando no cuidado de crianças e idosos, participando até com teatro de mamulengo e como palhaço, animando as festividades dessas Instituições. Apesar de ter identificado a cliente, através de levantamento de prontuários de pacientes agendados para pneumologia, nosso primeiro encontro real com ela ocorreu através de visita a sua residência, pois a mesma havia faltado à consulta ambulatorial, por estar em observação em outro serviço de saúde após atendimento de urgência. Essa experiência de contato pessoal, através de visita domiciliar, gerou expectativas, pois nós não sabiamos se encontrariamos sua residência com facilidade, se ela estaria em casa, nem como seriamos recebidas. Entretanto, tudo transcorreu da melhor forma possivel, pois ela foi bastante receptiva. Durante essa primeira visita a Nina, procuramos manter um diálogo informal com ela, o que possibilitou uma melhor apresentação nossa, como também uma explicação detalhada sobre o trabalho que estávamos desenvolvendo. Apresentamos-lhe o Termo de Consentimento Livre e Esclarecido, em duas vias, reforçando como se daria sua participação no estudo e o respeito a seus direitos e garantias. Após assinatura do documento, entregamos-Ihe uma das vias, onde destacava entre nossos dados, o número de nosso telefone, caso se fizesse necessário. De início, logo percebemos sua dispnéia leve, o que fazia com que conversasse com dificuldade. Por isso, não pretendiamos demorar, limitando-nos a marcar um novo encontro com ela, para o início da coleta de dados. Porém, a mesma demonstrava necessidade de desabafar, relatando, com muita fluência, sua realidade e seus problemas, possibilitando-nos, assim, conhecê-la melhor. Desse modo, a apreensão de informações para atender ao instrumento do estudo não se deu de modo seqüencial, pois necessitamos retomar questões que não haviam sido discutidas, através de visitas subseqüentes. Os dados coletados, nessas visitas, permitiram a identificação dos déficit de autocuidado, a partir dos quais foram feitos o planejamento, a implementação e a avaliação da assistência de enfermagem.

\section{IDENTIFICANDO OS DÉFICIT DE AUTOCUIDADO E SELECIONANDO OS SISTEMAS DE ENFERMAGEM}

Identificamos, em Nina, alguns déficit de autocuidado, procedendo a um planejamento assistencial com vistas à promoção de seu autocuidado, acreditando em seu potencial para a realização do mesmo. Inicialmente, evidenciamos o diagnóstico Dispnéia, a partir dos indicadores clínicos de respiração com esforço e desconforto aumentado relacionado com atividade física, respiração curta, mudança na intensidade da respiração, uso dos músculos acessórios, excursão torácica com sibilos, sensação de aperto no peito, verbalização de dispnéia diuturna e tosse diária com secreção espumosa.

Precisamos repensar as intervenções a serem propostas para o diagnóstico de dispnéia, pois estávamos acostumadas a lidar com o mesmo, em ambiente hospitalar. Desse modo, sentimos a necessidade de identificar que medicações a cliente está habituada a tomar e que procedimentos costuma realizar em seu ambiente doméstico, quando está dispnéica, informações consideradas essenciais para adequar as orientações à sua realidade. Foi, assim, orientada a realizar nebulização com maior freqüência, ou seja, quatro vezes ao dia, com medicação, mesmo que não esteja dispnéica e a retornar ao pneumologista para reavaliar sua terapia medicamentosa. No nosso retorno ao ambulatório e ao investigarmos seu prontuário constatamos que lhe havia sido prescrito corticóide a ser administrado através de dispositivo aerossol. Ao questionarmos o porquê de não estar fazendo uso da medicação, ela informou-nos que seu esposo não a tinha conseguido no posto e, ao tentar na farmácia, estava em falta, além de ser cara.

Realmente estava em falta a medicação prescrita na dosagem de $400 \mathrm{mg}$, nas farmácias, entretanto, conseguimos a de $200 \mathrm{mg}$, orientando-a sobre a necessidade de duplicar a dosagem, como também, sobre a técnica correta do uso do dispositivo de inalação, alertando-a para proceder higiene rigorosa bucal, após o uso da medicação, para evitar depósito da mesma, pois pode desencadear a ocorrência de moniliase oral. Reforçamos a importância dos cuidados que Nina afirmou realizar, como evitar situações que aumentassem a demanda de oxigênio, a exemplo de caminhadas muito longas e atividades físicas que exigissem muito esforço, respeitando seus limites físicos, frente ao descontrole da asma. Procuramos esclarecê-la sobre a importância de sua participação ativa, como de sua família, no controle da asma. Também a orientamos a evitar ou controlar desencadeantes da asma, como a poeira, atividades físicas, odores fortes, entre outros, sempre que possivel, estimulando-a a reconhecer os fatores que contribuem para o surgimento de suas crises, procurando lembrar-lhe as substâncias com que entrou em contato, os fatos que aconteceram naquele dia ou na véspera, ensinando-a e incentivando, ainda, para a prática da respiração lenta e eficaz. Orientamos a cliente a reconhecer quando a asma está fugindo de seu controle e a fazer uso das medicações de alivio, evitando crises graves. 
Para a execução desse plano terapêutico, visando o autocuidado, estabelecemos, como meta, controlar a dispnéia e, como objetivo, incentivar a cliente a verbalizar sua melhora e o controle de seu padrão respiratório e a demonstrar capacidade de se autocuidar. O sistema de enfermagem escolhido para a implementação de uma assistência planejada foi o apoio-educação e, como métodos de ajuda, a orientação, o incentivo e o apoio, sendo, através da orientação, desenvolvido todo um trabalho de aprofundamento de seus conhecimentos, como também, de esclarecimentos de dúvidas e entendimentos incorretos, priorizando o incentivo à realização do autocuidado, com base nas informações discutidas e no apoio para ela retornar ao ambulatório e ao tratamento de sua asma.

Os relatos de acordar-se durante a noite, com dificuldade para respirar, de apresentar crises freqüentes de asma, com atendimentos em serviços de emergências e até de ocorrências de internamentos devido à gravidade das crises, à dificuldade financeira para adquirir e manter o uso da medicação, ao uso do ácido acetil salicílico, à dificuldade nos procedimentos adequados para a manutenção da higiene doméstica, levaram-nos ao diagnóstico de Déficit de autocuidado no controle da asma. A assistência planejada para esse diagnóstico apresentou, como meta, diminuir o déficit de autocuidado no controle da asma e, como objetivo, levar a cliente a demonstrar autoconfiança, frente à aquisição de conhecimentos, principalmente em sua atuação diante das crises e na promoção do autocuidado no controle da asma. Foi selecionado, como sistema de enfermagem, o apoio-educação e, como métodos de ajuda, orientação, ensino através de exposição dialogada, palestra e apresentação de um guia para adultos que têm asma, proporcionando e mantendo um ambiente de apoio ao desenvolvimento pessoal e incentivo ao autocuidado. Assim, salientamos a importância do envolvimento e apoio de seus familiares no autocuidado, proporcionando, à cliente e a seu esposo, conhecimentos referentes à doença, esclarecendoos sobre o que é asma e quais os fatores que podem desencadear seus sinais e sintomas.

Carvalho e Rios (1982) destacam que o aparecimento de sintomas dessa doença, em casa, é sinal de alergia à poeira ambiental e, nesse caso, as condições de limpeza têm que ser avaliadas. Desse modo, procuramos orientá-la e a seus familiares sobre a maneira de proceder à limpeza doméstica, para o combate à poeira e aos ácaros, sem prejuizos para sua saúde. Estimulamos seus filhos a assumirem, também, os cuidados com a limpeza da casa. Inicialmente, demos maior ênfase à necessidade de limpeza diária da casa, com pano úmido, e ao uso de flanela, de preferência úmida, nos móveis, evitando-se vassouras e espanadores, que levam à suspensão e ao deslocamento da poeira, no ambiente, de modo a propiciar sua inalação pelas pessoas que se encontram no local, como também, seu posterior alojamento em móveis e no ambiente. Orientamos, também, evitar o uso de produtos de limpeza de odor forte, optando por pastas e sabão em pó, para a limpeza de banheiro e cozinha. Esclarecemos que tapetes, cortinas e almofadas tendem a acumular poeira, devendo ser evitados. Recomendamos afastar a cama da parede, priorizar a troca de roupa de cama duas vezes por semana, a evitar acúmulos de objetos no quarto. Ressaltamos a importância do hábito de abrir as portas e janelas da casa, para que pudesse ficar arejada e ensolarada, como também, a verificar, periodicamente, as áreas úmidas da casa, para se evitar o aparecimento de mofo. Reforçamos seu cuidado em não possuir animais com pêlos e no combate ao aparecimento de "pernilongos", "catitas", e, principalmente, "baratas", alertando-a sobre a necessidade de utilizar produtos, que, além de não apresentar cheiro forte, estejam submetidos à fiscalização de órgãos competentes.

Diante da presença das inúmeras fábricas em seu bairro, orientamos Nina e seu esposo para solicitar apoio à Associação de Moradores do bairro, a fim de pleitear, junto ao órgão responsável pelo controle ambiental, $\mathrm{CPRH}$ (COMPANHIA PERNAMBUCANA DE RECURSOS HÍDRICOS), a reativação da estação de monitoramento da qualidade do ar, na localidade, visto que a mesma estava desativada.

Tentamos conscientizá-la, ainda, sobre os medicamentos para o controle da asma e os de alivio, demonstrando-Ihe: a técnica correta de utilização dos remédios por via inalatória; os sintomas da crise de asma e seu tratamento precoce, afastando sua causa, quando conhecida; a necessidade de iniciar as medicações de alivio, alertando-a, enfaticamente, para a necessidade de manter um acompanhamento ambulatorial e da aderência ao seu tratamento.

A constatação do peso $20 \%$ acima do ideal, de inadequada ingestão de alimentos, a verbalização de um apetite aumentado e o desejo de emagrecer constituíram indicadores para o diagnóstico de enfermagem Obesidade. Inicialmente conversamos com Nina, de modo mais direcionado, sobre todos os prejuizos de seu excesso de peso, sobre a maneira de interferir em seus niveis pressóricos, em sua capacidade respiratória e nas condições para submeter-se a uma herniorrafia. Percebendo o seu interesse em colaborar com o enfrentamento da obesidade, realizamos algumas orientações básicas para esse fim, como: incentivála a comer lentamente, bem como, mastigar os alimentos completamente; restringir a ingestão de alimentos gordurosos e doces; fazer lanches de baixas calorias; ingerir mais verduras, bastante água nos intervalos das refeições e manter dieta hipossódica. Ressaltamos a importância de um acompanhamento específico e criterioso para ela, encaminhamos a o serviço de nutrição, chamando-lhe atenção para a importância do controle de sua asma, para que pudesse desenvolver caminhadas, respeitando seus limites orgânicos, auxiliando-a, assim, na perda de peso.

O planejamento da assistência proposto para o diagnóstico de obesidade determinou, como meta, controlar a obesidade, tendo como objetivo, levar a cliente a diminuir a ingestão de alimentos calóricos, a manter dieta balanceada, a apresentar adesão às modificações nutricionais e a demonstrar capacidade de autocuidar-se, priorizando-se, como sistema de enfermagem, apoio-educação e como método de ajuda, a orientação e o ensino, através de diálogo informal, sempre se respeitando seus conhecimentos prévios, socialmente construídos na prática comunitária.

Diante dos indicadores de presença de hérnia inguinal bastante proeminente, queixa de sensação dolorosa no local e relato de uso freqüente de ácido acetil salicilico, identificamos o diagnóstico Dor Crônica, na região peri- 
umbilical, estabelecendo-se, como meta, minimizar dor crônica e, como objetivo, estimular a cliente para assumir o autocuidado no controle da dor e referir diminuição de sua freqüência e intensidade, fazendo uso criterioso de analgésico, que possa ser utilizado por clientes asmáticos. Evidenciamos o sistema de enfermagem apoio-educação e os métodos de ajuda orientação e ensino através de exposição dialogada.

O tratamento curativo da dor crônica requer um procedimento cirúrgico para exérese da hérnia. Entretanto, a gravidade e o descontrole da asma, além de sua obesidade, constituem fatores que contra-indicavam tal procedimento. Ciente da necessidade de restabelecer condições propicias ao tratamento cirúrgico, numa perspectiva, em médio ou em longo prazo, para sua resolução definitiva, optamos por traçar, para o diagnóstico da dor, intervenções que conduzissem a um resultado mais imediato.

Para tanto, precisamos explorar um pouco mais sua experiência de dor, como: sua intensidade no pior e no melhor momento, sua freqüência e as situações que pudessem interferir em seu aparecimento ou elevação de sua intensidade, de modo que Nina referiu aumento da sensibilidade dolorosa por esforço físico e por fazer uso freqüente de ácido acetil salicilico. Chamamos a atenção da mesma para a necessidade de precaução no uso desse analgésico por pacientes com asma, como em seu caso, pois pode desencadear crises, orientando-a a consultar o médico sobre a utilização dessa medicação. Orientamos Nina a evitar pegar peso ou fazer esforço; a optar por decúbito, ao deitar-se, do modo que fosse mais confortável. Orientamos seus familiares sobre os usos terapêuticos da distração, juntamente com outros métodos de alivio da dor.

\section{AVALIANDO A ASSISTÊNCIA DE ENFERMAGEM NA PROMOÇÃO DO AUTOCUIDADO TERAPÊUTICO}

Durante o desenvolvimento das etapas do processo de enfermagem, constatamos que alguns fatores foram bastante relevantes para o alcance dos resultados obtidos por Nina, dentre os quais, destacaram-se: seu nivel de instrução, contribuindo para que participasse ativamente do processo ensino-aprendizagem, expressando suas dúvidas e apreendendo, com maior facilidade, os conteúdos trabalhados, através do sistema de enfermagem educaçãoapoio; a participação e o apoio dos seus familiares; o estabelecimento de um relacionamento terapêutico enfermeira-cliente-familiares.

Considerando a inter-relação existente entre os diagnósticos identificados de Dispnéia e Déficit de Autocuidado no controle da asma, constatamos uma evolução satisfatória dos mesmos, pois Nina apresentou melhora do padrão respiratório, demonstrando autoconfiança pela aquisição de conhecimentos essenciais para a promoção de seu autocuidado no controle da asma. Foram observadas atitudes corretas e imediatas, após constatação de ameaças de crises, atuando na prevenção e/ou tratamento precoce da mesma, evitando sua exacerbação e a necessidade de ser ela atendida em serviços de prontoatendimento.

Foram identificadas mudanças de atitudes, tanto da cliente quanto de seus familiares, os quais assumiam as tarefas domésticas durante o periodo em que a ela estava incapacitada, visto que tal esforço desencadeava-lhe crise. Por estarem conscientes da necessidade do combate à poeira e aos ácaros, presenciamos, em algumas de nossas visitas, o asseio da casa com pano úmido por seu irmão caçula ou por seus filhos, que tinham o cuidado de fechar a porta da frente, só abrindo-a, ao terminar o serviço, para que seus vizinhos não os vissem realizando afazeres domésticos, que para eles é atividade feminina. A percepção da realidade, enquanto profissionais da saúde, mostra-nos a inter-relação e a amplitude de fatores e causas envolvidos no lidar com as questões de saúde, fato que pudemos verificar em duas ocorrências de crise, decorrentes da utilização, por um vizinho do lado, de produtos derivados de petróleo, como óleo queimado e querosene, para combater infestação de cupim, evidenciando-se, assim, a necessidade de um trabalho educativo muito mais abrangente, não se limitando apenas ao cliente com asma e a seus familiares, mas, estendendose, também, à comunidade, como um todo, a qual carece de acesso às informações pertinentes à qualidade de vida.

Quanto ao diagnóstico de enfermagem Obesidade, a determinação e perseverança de Nina, seguindo as orientações quanto à dieta, promovendo sua re-educação alimentar, propiciaram-lhe a perda de cinco quilos, tendo sido observado que a diminuição de peso interferiu em sua autoestima, de modo que ela passou a arrumar-se mais, demonstrando maior disposição para assumir seus afazeres. Relatou adesão à dieta hipossódica, que repercutiu satisfatoriamente no controle de seus niveis pressóricos, que atingiram o pico máximo de $140 \times 110 \mathrm{mmHg}$, passando a apresentar o valor de $120 \times 80 \mathrm{mmHg}$, e, no edema da face e dos membros inferiores, tendo sido evidenciada sua diminuição, levando a cliente a reduzir a dosagem do diurético.

Com referência ao diagnóstico Dor Crônica, a cliente relatou mudança no tipo de analgésico utilizado, como também, critérios para sua utilização, pedindo que seu filho trouxesse o vidro de Tylenol $\circledast$ (paracetamol), medicação que conseguiu no posto, para usar quando sentisse dor. Comentou manter cuidados para não levantar objetos pesados, delegando essas atividades a um de seus familiares, e, ao deitar-se, procurar manter o decúbito lateral esquerdo, por ser contrário à localização da hérnia, entre outras ações paliativas, visto que o tratamento definitivo da sua sensação dolorosa, que é uma intervenção cirúrgica para exérese da hérnia, ainda aguardava condições mais adequadas, mais seguras, para sua realização.

\section{CONSIDERAÇÕES FINAIS}

Para operacionalizar o processo de enfermagem, neste estudo, optamos pela utilização da pesquisa convergente assistencial e pelo emprego da Teoria de Enfermagem do Déficit de Autocuidado, que constituíram instrumentos fundamentais para o desenvolvimento do processo de enfermagem, aplicado junto a uma cliente portadora de asma e seus familiares, visando a promoção do autocuidado. No seu desenvolvimento, ressaltamos que a realização das visitas domiciliares foi bastante significativa, levando em consideração a reconhecida influência que o ambiente domiciliar exerce no controle da asma, propiciando 
ainda, ao enfermeiro, conhecimento das condições reais do contexto familiar de cada cliente, de modo a propor-lhe ações factiveis e eficazes.

Tendo vivência na utilização dos diagnósticos de enfermagem, não só no ensino, mas, também, na prática assistencial, sempre os consideramos de significância ímpar, no desenvolvimento harmonioso e efetivo do processo de enfermagem; entretanto, até então, só tínhamos vivência com a aplicação da Taxonomia da NANDA. A opção por trabalhar, utilizando, também, a Classificação dos Fenômenos de Enfermagem da CIPE, Versão Alfa e Beta, constituiu para nós, um desafio, entre tantos enfrentados neste estudo.

O desenvolvimento deste estudo nos proporcionou uma aquisição de conhecimentos científicos, enriquecidos pelas vivências dos adultos portadores de asma, que revelaram um saber embasado em questões culturais e históricas, revelando seu cotidiano, ao lidar com as adversidades que se lhes apresentam, na busca de um modo de viver mais saudável.

\section{REFERÊNCIAS BIBLIOGRÁFICAS}

BRASIL. Ministério da Saúde. Conselho Nacional de Saúde. Comissão Nacional de Ética e Pesquisa CONEP. Resolução ${ }^{\circ}$ 196 de 10 de outubro de 1996 : Diretrizes e normas regulamentadoras da pesquisa envolvendo seres humanos. Brasilia, 1996.

BRASIL. Ministério da Saúde. Secretaria Executiva. Datasus. Sistema de Informações Hospitalares do SUS (SIH/SUS). Morbidade hospitalar do SUS, CID-10. Brasilia: 2001. Disponivel em: http://www.datasus.gov.br/cgi/deftohtm.exe ?sih/ rnbr.def. Acesso em: 25 de jun. 2001.
CARVALHO, L. C. P.; RIOS, J. B. M. Alergia clínica. Rio de Janeiro: Guanabara Koogan, 1982.

INTERNATIONAL COUNCIL OF NURSES. International classification for nursing practice. Genebra: ICN, 1999.

NETTINA, S. M. Distúrbios respiratórios em pediatria. In: Prática de Enfermagem. 6. ed. Rio de Janeiro: Guanabara Koogan. 1997. v. 3, cap. 42, p. 1016-21.

NÓBREGA, M. M. L.; GUTIÉRREZ, M.G.R. de. Equivalência semântica da classificação de fenômenos de enfermagem da CIPE: versão alfa. João Pessoa: ABEn/ldéia, 2000.

NORONHA, M. F. et al. Proposta de indicadores e padrões para a avaliação de qualidade da atenção hospitalar: o caso da asma brônquica. Cad Saúde Publ., Rio de Janeiro, v.12, sup. 2, p. 4358, 1996

NORTH AMERICAN NURSING DIAGNOSIS ASSOCIATION. Diagnósticos de Enfermagem da NANDA: definições e classificações 1999-2000. Porto Alegre: Artes Médicas Sul, 2000.

OREM, D. E. Nursing: concepts of practice. 5. ed. St. Louis: MosbyYear Book, 1995.

PEREIRA, C. A. C. et al. (Orgs.). Consenso brasileiro no manejo da asma. Jornal de Pneumologia, São Paulo, v. 24, n. 4, p. 171276, jul./ago. 1998.

RICHARDS, W. Hospitalization of children with status asmaticus: a review. Pediatrics., v. 84, p. 111-8, 1989.

TRENTINE, M.; PAIM, L. Pesquisa em enfermagem: uma modalidade convergente-assistencial. Florianópolis: UFSC, 1999. 